\title{
Sustainability Achievement and Estidama Green Building Regulations in Abu Dhabi Vision 2030
}

\author{
Khaled Ali Alobaidi \\ Dr. Abdrahman Bin Abdul Rahim 1 \\ Dr. Abdelgadir Mohammed 1 \\ Dr. Shadiya Baqutayan² \\ 1 UTM Razak School of Engineering and Advance Technology, Kuala Lumbur, Malaysia \\ 2 UTM Perdana School of Science, Technology and Innovation Policy, Kuala Lumpur Malaysia
}

\author{
Doi:10.5901/mjss.2015.v6n4s2p509
}

\begin{abstract}
Abu Dhabi is the capital of the UAE country and one of seven cities that composed the United Arab Emiratis. Abu Dhabi has a master plan for the future of the city in economic development "capital 2030"under the name of Abu Dhabi economic vision 2030 and the (Abu Dhabi Urban Planning Vision 2030).Abu Dhabi Urban planning cancel (UPC) drives and supports Abu Dhabi urban development strategy and transferring the vision 2030 physical settings and develops strategic development plans that create the guide principle that cascade over critical projects designed to shape the Emirate by a sustainable program under the name of "Estidama". Estidama the Arabic world of sustainability is not only a rating method or something that people do, it's a vision to achieve a new sustainable way of life in the UAE and Arab region. Estidama goal is to preserve and enrich Abu Dhabi physical and cultural identity and improving quality of live for residents in four equal pillars of sustainability: environment, economic, social and culture. The plan of Estidama in green building incorporates environmental considerations into every stage of building construction and focuses on design, construction, operation and maintenance phases. The aim of this paper is to review the Estidama pearl rating system (PRS) and to reveal how the green building system is suitable to develop and help the plan of Abu Dhabi (2030 vision). It's concluded that Estidama practice is an efficient tool in establishing the performance of residential building in the city of Abu Dhabi. Currently the research fields focus on developing a comfortable and energy efficient residential building design and also with construction sector through developing a building for the new generations.
\end{abstract}

Keywords: Abu Dhabi, Green building, Estidama, Pearl Rating System, cultural, Building design, Construction.

\section{Introduction}

\subsection{Background}

The seven Emirates that comprise the United Arab Emirates founded after 1971by sheikh Zaid ben Sultan Alnahyan.Abu Dhabi is the federal capital of the country and the largest Emirate including the most production of the oil and gas in the country(7).Abu Dhabi has evolved from having no sealed roads and only a small number of permanent building through to being one of the most important economic center Abu Dhabi urban planning council (UPC) is recognized internationally for large scale sustainable urban planning and for rapid growth. Abu Dhabi vision 2030 urban master plan addresses sustainability as a core principle. Abu Dhabi economic vision 2030 and urban planning vision which presents a combined overview of the entire Emirate through the development plans of the "capital 2030"Abu Dhabi metropolitan area (8).Abu Dhabi's plan2030 establishes a clear vision for sustainability as the foundation of any new development occurring in the Emirate and capital city of Abu Dhabi. This commitment is a reflection on the values and ideals of nations. More than just a sustainable program, Estidama is the symbol of an inspired vision for government and community development. It promotes anew mindset for building a forward thinking global capital.UPC has worked with the team guiding Estidama to ensure that sustainability is continually addressed through four pre-defined angles, environmental, economic, social and culture. Estidama goal is to create a modern sustainable framework that will improve the local practice in building sector and the life style for a long term in UAE. To make a new sense of responsibility with Estidama, UPC is going beyond other sustainable program to development around the world by creating a new tools, resources and procedures to be with vision 2030. It is the first sustainable practice and environment assessment method developed in the Arabian Gulf 
countries and the Middle East region. Estidama in Arabic language means sustainability and developed through Abu Dhabi planning council (UPC) in the year of 2008 in UAE (1). Estidama has a standard named Pearl Rating System (PRS) that will helps to deliver sustainable development efficiency.

The aim of PRS is to address the sustainability in a building throughout its entire life cycle design, construction and operation (1). PRS focuses on community buildings and villas and to help guide new development to improve the sustainability performance of the built environment. The (PRS) focused its initial efforts on the creation of community, building and villa rating systems which were launched on April $17^{\text {th }} 2010$. Estidama from the need to properly plan, design construction and operation the sustainable development with respects the traditions embedded within the local culture and on the other hand the harsh climatic nature of the region. The main challenges were to achieve the desire results to reducing energy consumption, reducing water consumption and building comfortable and environmental friendly residential area. This was conducted by evaluating the Estidama Pearls Rating System (PRS) to reveal how the Green Building procedures were implemented in residential buildings in Abu Dhabi. The findings suggest how the situation can be improved. The Pearl Rating System (PRS) is organized into seven categories that are fundamental to more sustainable development:

1- To integrate teamwork to deliver environmental and quality management throughout the project life.

2- Conserving, preserving and restoring the natural environments and habitats.

3- Improving the quality of outdoor and indoor spaces in the building projects.

4- Reducing water demand and encouraging efficient distribution of the water sources.

5- Reducing energy demand and renewable resources.

6- Ensuring about the materials life cycle and specifying materials.

7- Encouraging innovation in building design and construction for market and industry.

\subsection{Consumption Problem}

Abu Dhabi only gets around $100 \mathrm{~mm}$ of rainfall per annum as illustrated in Figures1. With negligible rainfall and restricted groundwater resources (10).

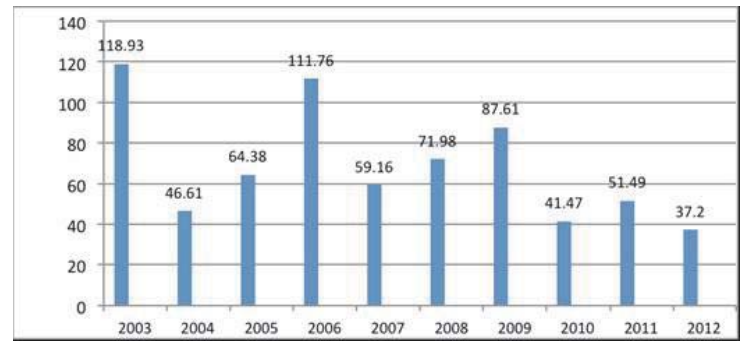

Figure 1 - Annual Rainfall in Abu Dhabi from 2003 -2012 (NCMS, 2012 ) (10)

Abu Dhabi additionally has extraordinarily hot temperatures that frequently exceed $40^{\circ} \mathrm{C}$ (As shown in Figure 2) which, in the absence of air-conditioning, would be intolerable and would greatly impact on productivity. Massive amounts of energy are presently needed for lighting, appliances and air-conditioning for homes (10).

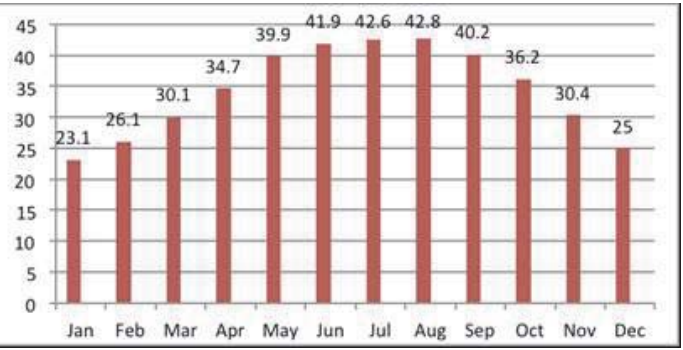

Figure 2 - Monthly Average Temperature in Abu Dhabi from 2003 -2012 (NCMS, 2012) (10) 


\subsection{Residential Building in Abu Dhabi and Estidama}

Abu Dhabi is the main city in the United Arab Emirates (UAE). It is the second largest city of UEA in population; the city had a population of 2.12 million in 2011 and also the biggest city in the country in area about 67,340 km2. Abu Dhabi is located on the Arabian Gulf coast (Abu Dhabi e Government Gateway, 2013) (10). In the year 1970s Abu Dhabi was planned for a maximum population of around 600,000. According to what was considered to be perfect urban planning at the time, the city has high-density tower blocks and a wide network of modern roads. The maximum population density is located on the northerly end of the island. In this area of towers there is a typical network of roads with lower density buildings between two-story villas to six-story. The(UPC) was established in 2007and its main authority responsible for the future of the city and Abu Dhabi urban environment and is the expert authority behind Abu Dhabi Plan 2030 to enhance the city's development through more than a twenty-five year program of urban improvement (UPC, 2011)(6). Due to the rapid development in Abu Dhabi, has some challenges to the organization of the city's urban environment have developed; today, the population has increased dramatically compared to the original designed maximum population. This has led to traffic congestion and the car parking shortages and overcrowding in the city center (UPC, 2011). Residential building numbers in Abu Dhabi have rapidly grown since 1968 until the year of 2010 in and the big change in this side (see Fig 3). (10)

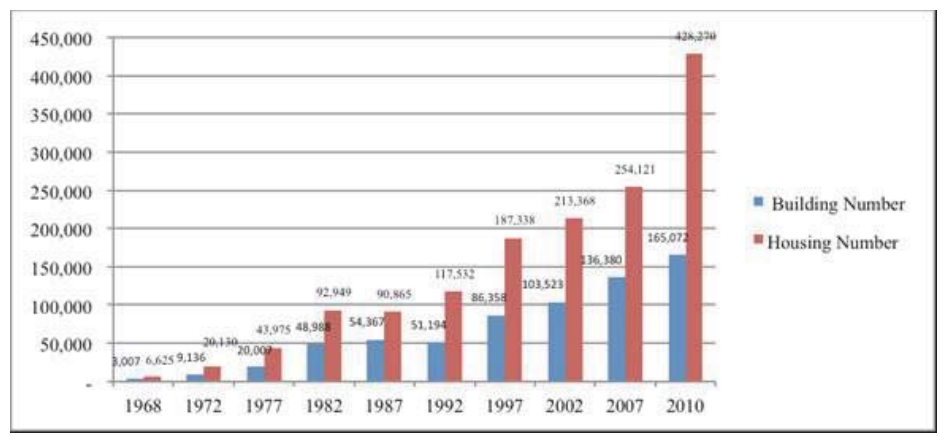

Figure 3 - The growth of building and housing in Abu Dhabi from 1969 up to 2010 (Abu Dhabi, 2010). (10)

\section{Pearl Rating System (PRS)}

\subsection{Estidama - PRS}

The Pearl Rating System has been the implementation tool for Estidama for the past two years. Every new building in the Emirate must now adhere to minimum sustainability requirements throughout the design and construction stages, with the operation and maintenance also assessed to ensure developments remain sustainable. Ensuring continuity of building performance remains a key concern for the UPC, which officially unveiled its Estidama Pearl Operational Rating Systemthe first initiative of this type in the region at Cityscape 2013(6). The Pearl Operational Rating System (PORS) will ensure the operational performance of buildings that have achieved a Design and Construction Pearl Rating under the (PBRS).The aim is to safeguard the operational performance of Pearl Rated Buildings and therefore achieve the high standards set for the sustainable building in Abu Dhabi city. It recognizes the transition between design, construction and operation and sets out the requirements that are vital for the successful lifecycle performance of green buildings. This will ensure Estidama buildings run efficiently and economically whilst offering occupants high levels of performance and comfort, and providing benefits to all building stakeholders, thereby extending both building and system lifetimes(10). The foundations of the(PRS)are integrated into(AUPC's) development review process via the planning for Estidama requirements(2). An Overview of the (PRS) Green Building Rating System covering its adoption within the UAE and key characteristics are presented in (tables 1,2) including the maximum credits of categories and (PRS) details and explanatory comments. 
Table 1: Estidama Categories and the credit distribution table: $(1,5)$

\begin{tabular}{|l|c|}
\hline Estidama categories & Maximum credit points \\
\hline Integrated development & 13 \\
\hline Natural and system & 12 \\
\hline Livable building & 37 \\
\hline Precious of water & 43 \\
\hline Resource of energy & 44 \\
\hline Steward and materials & 28 \\
\hline Innovation and practices & 3 \\
\hline
\end{tabular}

Table 2: Estidama Pearl Rating System (PRS) Overview $(\mathbf{1}, \mathbf{5})$

\begin{tabular}{|c|c|c|c|c|}
\hline Category & Details & \multicolumn{3}{|c|}{ Explanatory comments } \\
\hline UAE Market Penetration & $\begin{array}{l}\text { Forecasted to be very } \\
\text { high }\end{array}$ & \multicolumn{3}{|c|}{$\begin{array}{l}\text { The executive council has mandated a minimum Pearl Rating for all new construction } \\
\text { projects with Abu Dhabi (2010). There is no formal registration process for obtaining a } \\
\text { Pearl Rating. }\end{array}$} \\
\hline $\begin{array}{l}\text { International Market } \\
\text { Penetration }\end{array}$ & Not Applicable & \multicolumn{3}{|c|}{$\begin{array}{l}\text { The PRS is tailored to Abu Dhabi's unique climate, culture and transformational } \\
\text { ambitions. Many of the requirements are linked to specific codes and guidelines relevant } \\
\text { to Abu Dhabi. Therefore it cannot be easily transported to areas outside UAE }\end{array}$} \\
\hline Rating Scheme & $\begin{array}{l}\text { Points assigned to } \\
\text { credits }\end{array}$ & \multirow{2}{*}{\multicolumn{3}{|c|}{$\begin{array}{l}1 \text { or more points assigned to each credit. } \\
\text { Points achieved by meeting specified performance thresholds or perspective compliance } \\
\text { paths }\end{array}$}} \\
\hline Weightings & No & & & \\
\hline Certification levels & Tiered & \multicolumn{3}{|c|}{ One pearl, two pearls, three pearls, four pearls, five pearls } \\
\hline \multirow[t]{3}{*}{ Applicability } & \multirow{3}{*}{$\begin{array}{l}\text { Several Building } \\
\text { Types across Life } \\
\text { Cycle }\end{array}$} & New Co & unities & Not Applicable \\
\hline & & $\begin{array}{l}\text { New Bu } \\
\text { Residen } \\
\text { etc.) Nev }\end{array}$ & $\begin{array}{l}\text { ngs (General, } \\
\text { Retail, Office, } \\
\text { illas }\end{array}$ & Existing Buildings Program and Operational Rating \\
\hline & & Design & Construction & Operation \\
\hline International Adaptability & Very Low & \multicolumn{3}{|c|}{ Adapted to serve Abu Dhabi's needs } \\
\hline Information Collection & $\begin{array}{l}\text { Design Team and } \\
\text { PQP }\end{array}$ & \multicolumn{3}{|c|}{$\begin{array}{l}\text { The PQP is an individual on the project stuff to help in that understand (PRS) certification } \\
\text { process for a development }\end{array}$} \\
\hline Assessment Body & UPC Assessors & \multirow{2}{*}{\multicolumn{3}{|c|}{ UPC Assessors assess the PRS submissions to do a connect with PQP }} \\
\hline $3^{\text {rd }}$ Party Verification & No & & & \\
\hline Certification Body & (UPC) & \multicolumn{3}{|c|}{ Abu Dhabi urban planning council is the certification body. } \\
\hline Audit (Post-construction) & Mandatory & \multicolumn{3}{|c|}{ Construction Rating is mandatory and linked to Building Completion Certification. } \\
\hline
\end{tabular}

\subsection{Pearl community rating system}

The main goal of Pearl community rating system (PCRS) is to develop sustainable communities and improve the quality of the life in estidama projects (2). PCRS encourages water, energy, waste minimization and aims to improve supply chain and materials recycle management. All new communities developments must meet the (1pearl) requirements starting in June 2010.The PCRS is applicable to developments that are multiple plot subdivisions with vehicular network and community facilities or amenities a fundamental pearl of PCRS(3).the PCRS designed to be used for development projects wish will support a minimum permanent residential population of 1000 people, this being the minimum population for wish community facilities are required to be provided in accordance with the UPC community facilities requirements. Now all community projects eligible for a pearl rating are reviewed by UPC and project team only $(1,2,9)$.In figure 4 Pearl community rating system credits.

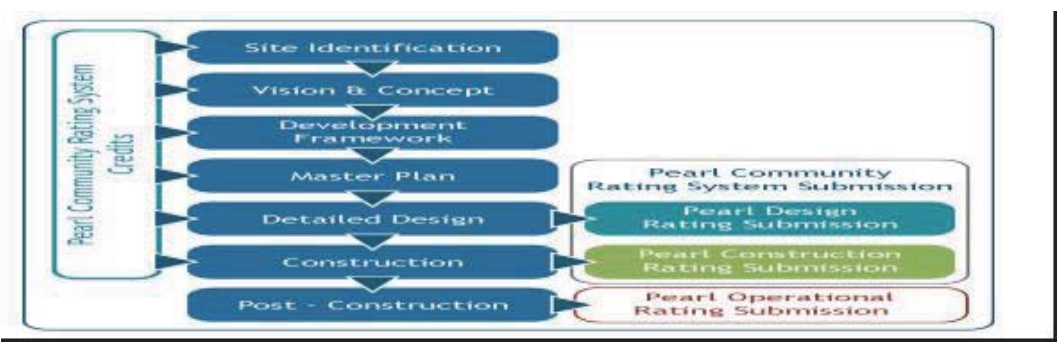

Figure 4 - Integration of community rating system into the design process 


\subsection{Pearl Building Rating System:}

To achievement the sustainable building requirements the integration of four pillars of Estidama practice with a collaborative the integration development process. Pearl Rating Building system (PRBS) aims to improve supply chain system for sustainable and recycled materials and products. All new building should meet the minimum requirement as (1 pearl) and the government building as (2 pearls) to be following Abu Dhabi development and building code $(3,9)$. The PRBS is applicable to all building type, sites and facilities including hospitals, workshops, laboratories, warehouses, and hotels.

\subsubsection{Building typologies requirements}

1- Office: the office spaces requirement such as meeting room, staff room, reception, waiting area, corridors, store room and services room.

2- Retail: sale of good and the convenience stores, restaurants, also including shopping center, department and retail stores.

3- Multi residential: for multi-family residential development villas and must to be using the system of Pearl rating Villa System (PRVS).

4- School: for both primary and secondary school, collages, higher education organizations, and all levels of education institutions.

5- Mexed uses: for all combinations of any two or more of the above categories or any relevant credits for the program.

If any building achieved (PRBS) rating than will be evaluate by the (UPC), otherwise should be register and follow the building process and submit it again by process outlines $(1,2)$ and table-3.

Table 3 - Pearl Building Rating levels (PRBS-2010)

\begin{tabular}{|l|c|}
\hline Requirements & Pearl rating achieved \\
\hline Compulsory credits & 1Pearl \\
\hline Compulsory credits +60 credits points & 2Pearl \\
\hline Compulsory credits +85 credits points & 3Pearl \\
\hline Compulsory credits +115 credits points & 4Pearl \\
\hline Compulsory credits +140 credits points & 5Pearl \\
\hline
\end{tabular}

\subsection{The Pearl Rating Process}

This is designed to be a simple and active way of learning to evaluate the sustainability of a specific development. The general stages that developers and consultants in the process must follow are summarized below Table 4. (10).

\begin{tabular}{|l|l|}
\hline Steps & Requirements \\
\hline Step 1 & Estidama registration form for pearl rating system \\
\hline Step 2 & PQO appoint and submission \\
\hline Step 3 & Workshops and Estidama integrated development \\
\hline Step DR4 & Review and credit submission for design process \\
\hline Step DR5 & Final design and construction documents submit \\
\hline Step DR6 & Pearl assessor and checklist requirements \\
\hline Step DR7 & Pearl design rating by the pearl assessor \\
\hline Step CR4 & Update and review the credit submission \\
\hline Step CR5 & Final submission to Estidama after complete \\
\hline Step CR6 & On the site verification if necessary by Estidama \\
\hline Step CR7 & Pearl construction rating on the credits achieved \\
\hline
\end{tabular}

\subsubsection{Pearl Rating System review process}

Firs submit the application of pearl rating system to (UPC) than Estidama team review and feedback to both project owner and project professional by necessary comments. The review processes in the flow chart below (3) see figure-5 


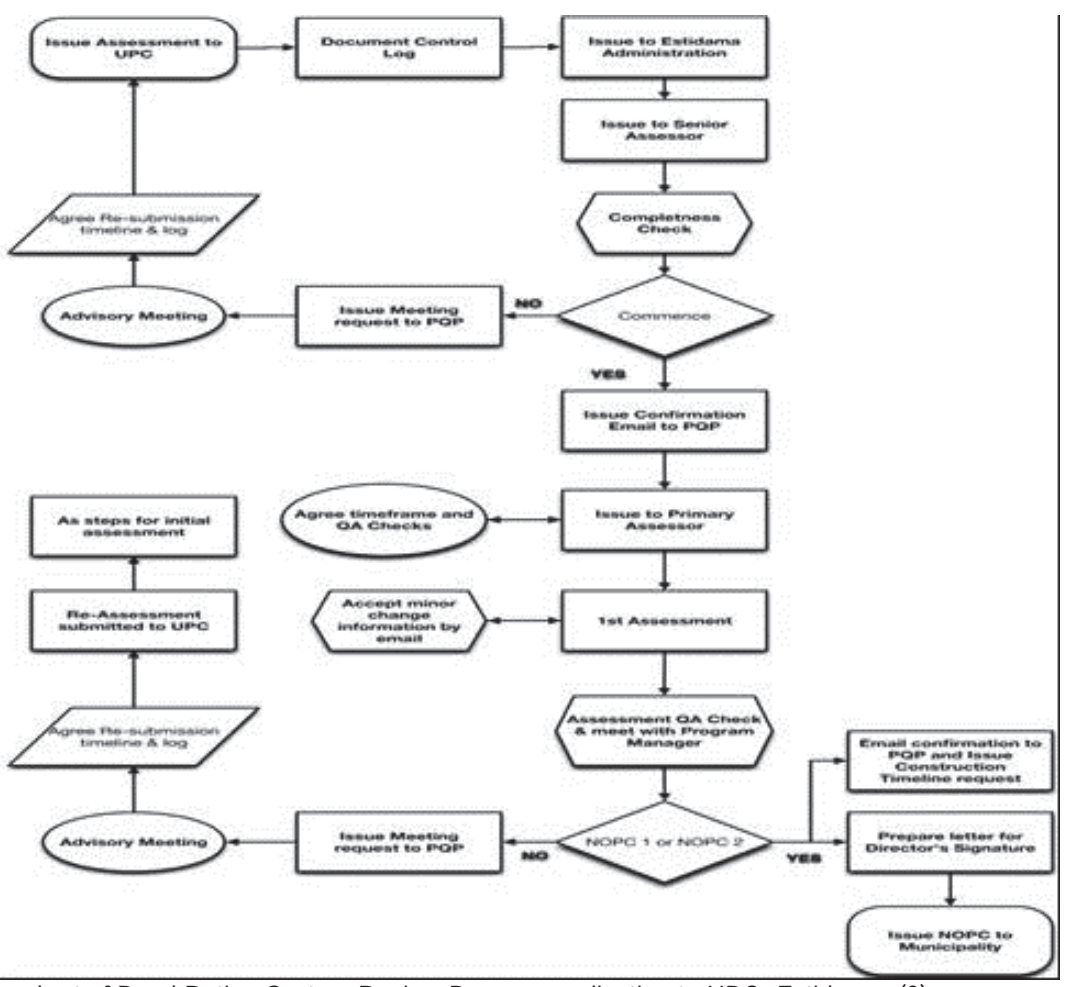

Figure 5: Flow chart of Pearl Rating System Review Process application to UPC- Estidama. (3)

\section{Benefits of complying with Pearl Rating System}

Operation efficiency, water and energy reduce, cost and maintenance reduce, better quality and market ability improvement. The system organized in seven categories some mandatory and some is optional and all the mandatory system should meet the minimum requirements of pearl rating 1 pearl and credit points (9) see figure-6.

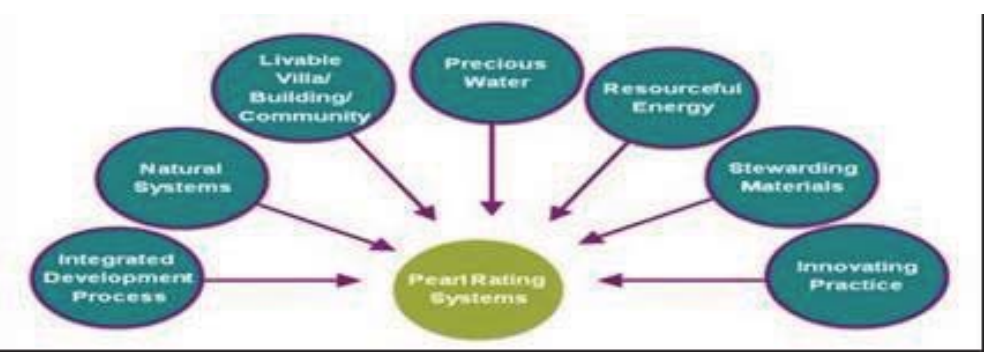

Figure 6: the seven categories to achieve the minimum (1) pearl rating for final approval from UPC (9).

\section{Estidama \& Development Review}

To start any new project need permission from the ( UPC) and necessary to development and building projects.Vision2030 requirements to follow Estidama pearl rating system and submission process for each stages of the project. Achieve the design requirements before obtaining the permission of building project and from the municipalities (3).showed below figure- 7 . 


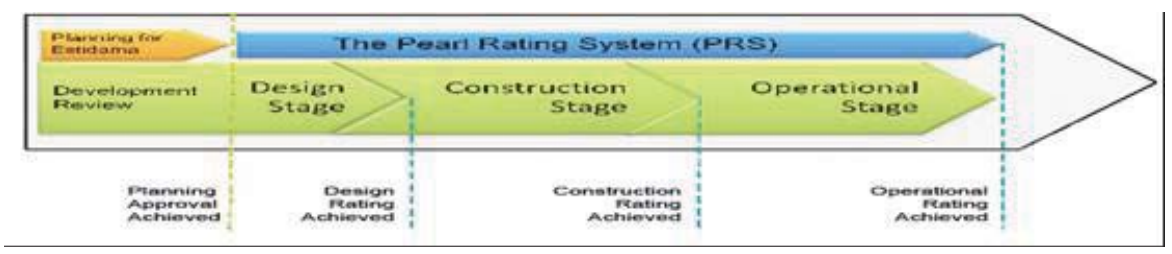

Figure 7: The Development Review Process of Estidama requirements and design rating (3).

\subsection{Objectives of Estidama Practice}

- Undertake assessments of Pearl Rating System (PRS) submissions.(9)

- Provide customer support, including review meetings, workshops and training.

- Develop Estidama related policies and to actively participate in the review of UPC regulations guidelines and policies to ensure consistency with Pearl Rating System (PRS) requirements.

- Increase public awareness of Estidama and promote sustainable development by creating products and services that address one or more of the four pillars of the system.

- Actively engage development teams and Estidama stakeholders through regular communication mechanisms and enable the Development Review team and the overall UPC to be viewed as a customer service driven agency.

- Raise the profile of the Estidama brand, its associated credentials (e.g. Pearl Qualified Professionals - PQP) and certifications (e.g. PRS Design/Construction Ratings) both at the Federal and International level.

\subsection{Pearl Rating system achievements:}

More than 110 projects has received rating from Estidama program which comprise about 2.7 million $\mathrm{m}$ `2 of ground area and 50 projects currently under construction.16 projects have received rating in education field which 10 schools are 3pearl rated. More than 9 building pearl rated in Ports Company. The number of pearl qualified professional is 890 persons. Construction audits is 197 and the trained people is 5800.

\subsection{Pearl Rating System Stages and Process:}

1- Design rating: is only valid until construction complete and when the project rated.

2- Construction rating: when the construction activities and project achieved the design intent.

3- Operation rating verifies the operational performance and the development the design to achieve the objectives of project (9). see figure -8 .

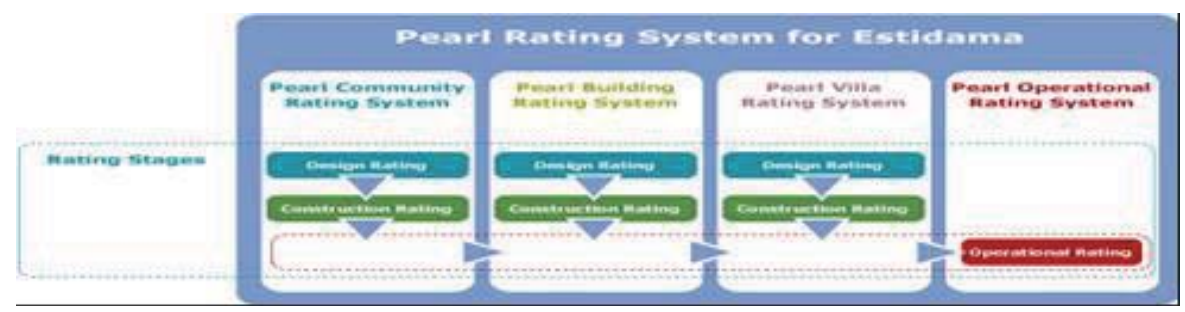

Figure 8: Pearl rating system and stages of certification. 


\section{Estidama Four Pillars}

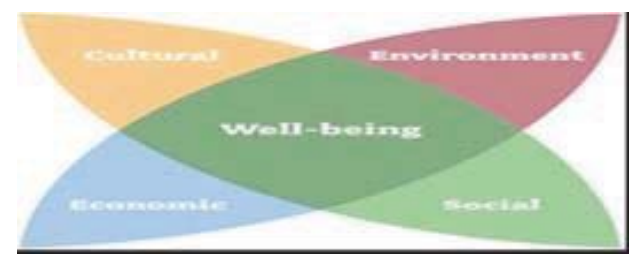

Figure 9: The Four Pillars of Estidama (Environment, Economic, Social and Culture) (11).

\subsection{Environmental Sustainability}

The government of Abu Dhabi will insure that the development of professionally designed and managing the urban environmental. Also to be sure the environment in the city is remain a safe place to visit, work and life.UPC has developed and published comprehensive frameworks for Abu Dhabi environment such as:

1) Reduce the demand of materials and the consumption of energy and water.

2) Reduce water and air pollution to protect the general health in society.

3) Decrease the greenhouse gas emission by develops a protective response of climate change (8).

\subsection{Economic Sustainability}

Uncontrolled economic growth is either sustainable or desirable, as well as being expensive in terms of both infrastructure investment and loss of cultural identity. A city must be able to generate jobs and provide a range of services that meet the needs of all its inhabitants. To do so, it must attract investment to the city and be prepared to invest publicly in the facilities, infrastructure and public realm. It must be able to provide businesses with the services they need to operate competitively. To do this well, the city must have a Government that is administratively efficient, financially sound, business oriented (in terms of ease of business, low taxes and favorable costs of doing business) and far-sighted in its planning. To prosper, cities must be open to new ideas and participate actively in the global economy. It must have trade opportunities with other cities and economies of the world in order to benefit from the richness of the globalizing economy (8).

\subsection{Social Sustainability}

Social sustainability encompasses a range of elements to enable future generations to have the same or greater access to social resources as the current generation. Social resources include basic human needs such as food and shelter, community facilities such as educational and healthcare centers, along with employment opportunities and safe living and working conditions. However, social sustainability goes further than just providing physical assets. Having an ethical and transparent Government that instills fair laws relating to human rights, labor laws and social justice is also key to creating a content and sustainable society. Furthermore; citizens must feel that the benefits of development are distributed fairly across society and across the region. The UPC is ensuring that the development of Al Ain and Al Gharbia keep pace with Abu Dhabi City to ensure an even distribution of social benefits through their physical development as well as policies and regulations that provide for fair housing opportunities (8).

\subsection{Culture Sustainability}

Cultural sustainability includes human capital, such as knowledge and skills, and cultural capital, such as local social relationships and customs. It is distinct from social Sustainability as cultural heritage and customs form the foundations of society. As Globalization and urbanization increase, it is important that culture is not eroded as this could reduce the ability of a nation to contribute innovations that spring from their unique geographical settings, culture, identity and history. Preserving local culture and diversity remains a crucial task for cities. Many of Abu Dhabi's customs stem from the unique links between the sea, desert and the Bedouin tribes, as well as its climate. Therefore, much of the cultural sustainability lies in maintaining these ancient links along with the skills and intangible knowledge that was passed from 
generation to generation. The Bedouin lifestyle was inherently sustainable, which makes the passing of this knowledge to future generations all the more important (4).Recently the Abu Dhabi Government has strongly focused on planning and building high-quality, modern, sustainable homes that build on Emirati traditions and heritage (shown in Figure 10) . These developments consist of communities of flexible and adaptable homes with a network of pathways and streets that link people to places and community services that meet the requirements of the residents along with open places for meeting and recreation; in short they support a lively and cohesive society. The new housing provides around 5000 homes for Emirati families. The rapid development of residential buildings in terms of quantity, quality and style of construction is a major achievement in Abu Dhabi, but the biggest achievement is the transformation within a few years from conventional building to green building. Today, all the new villas have to achieve a minimum Estidama rating system. (8).

\subsubsection{Culture Objectives}

1. To protect and enhance Emirati and Arab culture and traditions while embracing contemporary living and respecting the diverse cultures of all who reside in and visit Abu Dhabi.

2. To ensure that Emirati culture and local heritage is protected, enhanced and celebrated through traditional living patterns, sustainable, high-quality Emirati architecture and appropriate religious amenities.

3. To respect and integrate, where possible, the international cultures of the diverse population of the Emirate. To incorporate areas for local and international arts, music, civic and cultural usage those are accessible to all who live and visit the Emirate of Abu Dhabi.

\subsubsection{Culture and the style of houses}
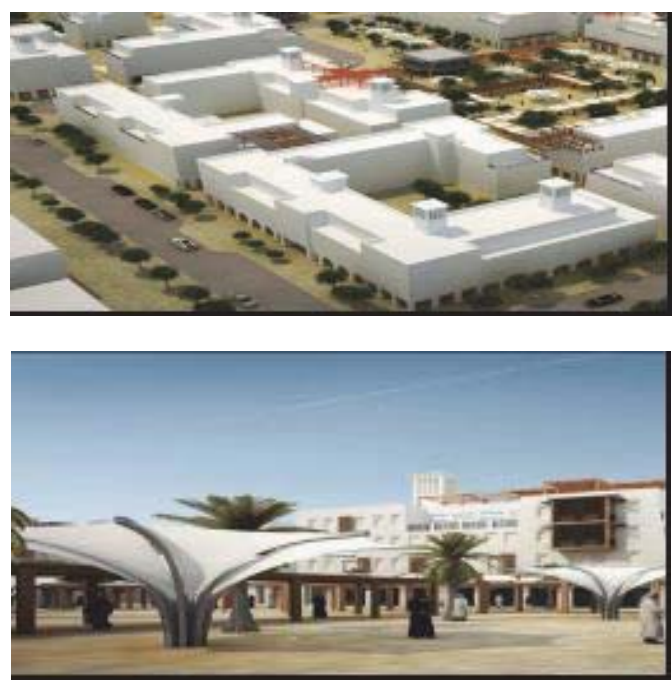

Figure 10: The local traditional neighborhood concept, Al Fareej -Emirati Housing style and designing (4).

Abu Dhabi and UPC started the project of communities Fareej design the traditional neighborhood system for the local residential houses. The strategy concept is that to build cultural houses with local traditional style and privacy for the family. Sikkak is a spaces between houses provide cool, safe and walkable routes to Barahaat that are spaces between homes and to create focal points for residents to come and interact all people.UPC is actively work with all developers to incorporate Fareej design in future projects. A brochure, highlighting the vision for Fareej neighborhood design was released in early 2010 and a detailed Neighborhood Design Manual, is due for release in 2011. The manual will be produced to prescribe appropriate standards for the elements of the Fareej, thereby providing a clear direction for developers (4). The tangible benefits of this approach include:

i. Targeting $50 \%$ reduction in annual energy consumption compared to reference building. 
ii. Anticipating $15 \%$ of energy balance to be provided by renewable sources.

iii. High performance envelope, reducing peak external heat gain by $70 \%$ compared to reference building.

iv. Water use reduction by over $75 \%$ from a comparable building.

v. Construction waste diversion from landfill expected to exceed $50 \%$.

vi. Creating a building that by its design tells a compelling story of Estidama without requiring extensive exhibits or narrative (12).

\section{Conclusion}

This paper presents a complete review of Estidama green building practice in Abu Dhabi -UAE and in the GCC region. Estidama driving this concept to improve the sustainability practice in Abu Dhabi and ground them in the pillars of environment, economy, social and culture needs in UAE and GCC region through some regulations and frameworks. Estidama has plan for a bright future for Abu Dhabi, citizens, residents, and the generations. Success of Estidama program will depend on different elements such as the people working together to create a better future for all. UPC encourages developers, private individuals to look to costs through the design, development, construction and operation of their projects. Sustainable visions is in the future to enhance economic development, manage urban growth, and improve connectivity within the city plan and to be including safer streets and bring diverse range of houses options. To insure neighborhoods and communities meet all their needs in a private houses and preserve cultural heritage and protect the natural environment. This practice will develop and improve the sustainable knowledge in the Middle East region comparing to the developing countries. Raise the profile of brand of UAE practice in residential building through Estidama and try to be in advance level with breeam and leed practices to develop new regulations to improve the construction sector in the United Arab Emirates. To develop Abu Dhabi's cultural character by improving quality of life for its residents based on four elements of sustainability such as ecological, financial, community and social.

\section{References}

Abu Dhabi Urban Planning Council (AUPC) 2010 Pearl building Guide, Estidama.PP. 1- 72, 2010.

Abu Dhabi vision 2030, sustainable development in practice-Review and Analysis, 2012.Chapter of: Proactive development strategy, PP. 4-51.

Estidama website, http://www.estidama.org/estidama--development-review- 2010 Abu Dhabi Urban Planning Council.

Abu Dhabi Urban Planning Vision 2030 - www.adced.ae. / Neighborhood Design Manual 2011, PP. 1-200.

Re-Green Project Coordinator / Green Building Policies - International Cases-case-of Abu-Dhabi: Pearl Rating System Code for Estidama's sustainability framework

Abu Dhabi Urban Planning Council.(2011). Abu Dhabi Vision 2030.Abu Dhabi Urban Planning Council Website, Retrieved 2011 from http://www.upc.gov.ae

Abu Dhabi e-Government Gateway.(2013). Abu Dhabi Emirate: Facts and Figures. Abu Dhabi e-Government Gateway Website, Retrieved 2013, from https://www.abudhabi.ae

Abu Dhabi Urban Planning Vision 2030 -www.adced.ae/ Abu Dhabi Economic Vision 2030 -Abu Dhabi Urban Planning Vision 2030.

The Pearl Rating System for Estidama-http://estidama.org/estidama-and-pearl-rating-system/pearl-rating-system.

Shahnaz Ali Abdalla Mohammed, Mohamad SyazliFathi, NoorizzaMohdZaki (2014) UTM, Implementing Green Building Procedures for the Construction of Residential Buildings in Abu Dhabi.

The Pearl Rating System for Estidama- Community Rating System Design \& Construction Version 1.0 - April 2010- page; 1 of 172

Estidama program: Moving Abu Dhabi toward a Sustainable Future - Abu Dhabi Sustainability Group Quarterly Meeting. PP: 1-29 